\title{
Proper homes, toilets, water and jobs: a new approach to meeting the modest hopes of shackdwellers in Cape Town, South Africa
}

\author{
S. Jiusto \& R. Hersh \\ Interdisciplinary and Global Studies, Worcester Polytechnic Institute, \\ USA
}

\begin{abstract}
With the global need for new approaches to sustainable development in periurban "slums" as a backdrop, this paper reports on an innovative approach to community-based, in situ informal settlement upgrading in the Monwabisi Park community of Cape Town, South Africa. The program is an experimental effort to combine the creative resources of parties that often have difficulty working together to nurture local self-help efforts that, with judicious and limited outside resources, can lead to sustained provision of improved community services and infrastructure. Starting with a local street committee's creation of a children's crèche in 2005 and partnering with a small local NGO, the Indlovu Project has established a set of public amenities and a vision for the future that combines western sustainable development concepts such as permaculture with Xhosa cultural sensibilities regarding equity, ubuntu, collective decision-making and the nature of private and public spaces. The Worcester Polytechnic Institute (WPI), a US university, has through an experiential science-technology-society educational program begun engaging students and faculty members with community members and city agencies to develop an integrated plan for transforming the eleven year old Monwabisi Park squatter camp into an "ecovillage" based on these local community perspectives and desires. This paper discusses the principles and strategies underlying the redevelopment effort; explores how students can be uniquely positioned as agents of redevelopment; and presents some of the unique strategies and services that are emerging through this collective effort.
\end{abstract}

Keywords: informal settlement upgrading, urban sustainability, experiential learning, undergraduate education. 


\section{Introduction}

In South Africa, some 2.4 million households or one-sixth of the population, live in shacks in informal settlements that have grown rapidly since the overthrow of the apartheid system removed legal constraints on internal movement of the country's black majority [1]. As rural dwellers have migrated to cities in search of economic opportunity, many have squatted on open land in or near apartheidera black townships, building tin shacks and staking a claim to land rights long denied them. While complex, heterogeneous places of great vitality, people in informal settlements also suffer from high levels of poverty, crime, and inadequate provision of health, education and social welfare. Informal settlements reflect not only South Africa's particular social and historical context, but global processes of economic integration, exploitation and urbanization that has one quarter of humanity's urban population living in slums [2]. They pose a major challenge of the 21 st century - how to foster conditions conducive to sustainability in urban environments that will allow slumdwellers opportunities to realize their ambitions for safer, healthier, more prosperous communities?

The daunting nature of the challenge of sustainable community development in the complex socio-technical space of urban informal settlements is evident in the paradox between the South African constitution's assertion of individual rights to housing, water and sanitation, and the agonizingly slow, conflictual and often failed process of attempting to realize these rights [3, 4]. In Cape Town, only 10,000 new homes are provided annually, against an estimated backlog of 400,000 eligible families [5]. Worse yet, the standard "sites and services" approach to upgrading settlements through greenfield or "rollover" development is highly disruptive and contentious, and is much more successful in serving the interests of private developers than poor people's need for healthy, sustainable communities [4]. In 2005, the national government adopted a new housing policy, Breaking New Ground [6], that opens up new opportunities for communities to shape their own development trajectory through incremental in situ settlement upgrading strategies that are more "people-centered," avoid mass relocations, and build on existing community strengths and institutions [3]. Despite these "housing" policy developments and national and local embrace of sustainability goals and policies, few examples exist in Cape Town today of compelling, sustainable approaches to successful informal settlement upgrading [though see 7 for one case study in early development].

In this paper, we argue that settlement upgrading is a socio-technical process and that many of the barriers to successful outcomes stem from disjunctures in how key actors understand and engage practically and institutionally with the "social" and "technical" dimensions of the challenge. For over a decade, the state generally sought to "eradicate" informality through technological (and technocratic) means: move the people, bulldoze the land, create a grid of roads, lay water and sewer pipes, erect a small (typically block) house, move the people back in, subtract them from the waiting list and add the houses to the tally of successful homes built, and leave. Much engagement with community involved 
trying to manage outrage at disruption to social and livelihood networks that occurred as the process played out, typically over years and involving multiple city departments working on parallel, minimally coordinated tracks. The People's Housing Process and other approaches that seek a greater role for communities often struggle to manage complex internal political and institutional dynamics and to interface effectively with key agency personnel who as engineers, planners or managers often lack training in how to work with communities, especially across cultural and social boundaries [8]. Conversely, community members and organizers, NGOs, politicians and social science critics typically have a limited understanding of the technical and economic dimensions of buildings and utilities infrastructure, and neither group is likely to appreciate the strong social and political ramifications that choice of alternative technologies can carry [9]. As a result, progress has been slow and circumscribed.

The challenges of transformation and development in complex sociotechnical systems are not unique to informal settlement upgrading "sustainability science" scholars and those interested in "sustainability transitions" in key industries (e.g., electricity, transportation, etc.) regularly find that progress is inhibited by the momentum of interests, power, and institutional arrangements that support and maintain entrenched practices and policies [10, 11]. Alternative approaches and technologies confront economic, legal, and institutional costs that make their implementation even on small scales difficult. Further insights are found in the literature on the science-policy interaction, which stresses the critical role of effective communication and collaboration across boundaries of discipline, bureaucracy, and culture [12, 13]. Such insights have led to increased emphasis on better preparing undergraduate science, technology, engineering and mathematics (STEM) students to work effectively on such problems, especially by offering students experiential learning opportunities to work closely with organizations on sustainability research and problem-solving [14]. This paper discusses one such program, the WPI Cape Town Project Centre program, and how students engaged there represent a unique resource for bridging some of the various divides that often thwart effective collaboration for sustainable development.

\section{Program background}

The WPI Cape Town Project Centre is part of WPI's Global Perspectives program through which undergraduate students may fulfill a degree requirement for an interdisciplinary, society-technology research project. The project experience has a significant impact on student development [15] and is regularly identified by students as both the most demanding and rewarding experience of their undergraduate career. Projects involve two months of preparation oncampus and two months full time research on site.

In 2007, the first group of two dozen students traveled with two faculty advisors to Cape Town to conduct projects. Students worked in teams of 3 or 4 in close collaboration with a local city agency or organization, focusing on 
critical needs, limitations and best existing practices in informal settlement upgrading. Our work confirmed both the interest of many city professionals in improving conditions in settlements and the difficulty they experience trying to collaborate with communities and others to do so [16]. One key impediment is the bureaucratic balkanization of those city functions most closely connected to settlement communities. Housing, water and sanitation, disaster relief, stormwater management, electricity and trash removal, not to mention "soft services" like education, training, and public health are all separately managed functions. Interagency collaboration (and basic service delivery) is complicated not only by common bureaucratic barriers of time, budgets, competing interests, differing professional and disciplinary outlooks, but also by ongoing upheaval in the bureaucratic ranks as the newly democratic nation opens opportunities to blacks and coloreds, while experiencing white flight and regular reorganizations. Meanwhile, governance structures in settlements are themselves complex and poorly understood by outsiders (and often by community members), and collaboration with communities is difficult. Many agencies have responsibilities extending over scores of Cape Town's 220 informal settlements, with social, cultural, and language barriers adding to the fact that few staff members have training relevant to working in these complex, challenging environments.

In 2008, we responded to these difficulties by concentrating our efforts in one informal settlement in Monwabisi Park, a squatter camp of 5,000 households located in Khayelitsha, Cape Town's largest and most peripherally located township. The community and its NGO partner, the Shaster Foundation, over the previous 2 years had launched the Indlovu Project, a set of programs and public facilities to meet local needs, including a crèche, health clinic, youth centre, community gardens, soup kitchen, craft centre and tourist guest house (www.shaster.org.za). The project is guided by principles of sustainable development and permaculture, emphasizing local decision-making and selfsufficiency, employment, community strengthening, and ecologically friendly design. In 2007, one WPI team worked with the community to design and build a communal laundry facility. In 2008, WPI was asked to lead a planning process that would draw on these important community assets and development principles to begin creating a clear plan for transitioning the settlement from informal shacks and inadequate services to a sustainable, vibrant 'eco-village.' The vision is of a community that uses the redevelopment process to create jobs and services, learning opportunities, clean and renewable energy, water and sanitation systems, and locally constructed, high quality, energy efficient and healthy houses for residents.

To this end, six student teams were formed, focusing respectively on communications, mapping and urban planning, buildings, water and sanitation, energy, and economic development. All teams conducted research in three phases: 1) rapid assessment of existing community conditions, including social and physical infrastructure and people's concerns and priorities for the future; 2) creation of a portfolio of options and recommendations for future redevelopment; 3) implementation of "prototypes" - programs or small-scale construction projects that students could start immediately with local 
involvement in response to expressed community needs. Two months was not long enough to thoroughly investigate any of these issues. Instead, the goal was to identify key issues, evaluate options, and lay a foundation for ongoing collaboration. Below, we discuss key outcomes of this initial phase of planning for in situ sustainable community redevelopment organized around three key themes - multi-sectoral and interdisciplinary collaboration, community engagement, and local capacity development - that represent domains of congruence between important, but hard to achieve goals of people-centered settlement upgrading, and the goals and capacities of experiential learning programs for undergraduate students.

\section{Facilitating multi-sectoral, interdisciplinary collaboration}

There is wide agreement among sustainability scholars, development practitioners and critics, and educators that most major challenges facing humanity require the growth of rich collaborative networks able to bring diverse perspectives and problem-solving capacities to bear. With respect to informal settlement upgrading, there is need for effective collaboration across sectors (including community leadership and citizens, city agencies, NGOs, private businesses, and academics), across disciplines (technologists, social scientists, artists), and across bureaucratic silos, including those with both "technical" responsibilities (housing, energy, water, stormwater management, waste removal, etc.) and social responsibilities (education, health, job training, etc.). In its second year in Cape Town, WPI found itself surprisingly well-situated to facilitate networking and collaboration, in part because our 2007 projects had, by design, involved challenges across a number of complementary development topics, but also because our city partners all were interested in taking advantage of students' time and interest in researching and evaluating "who was doing what" and to develop recommendations for combining insights and sometimes programs.

Collaboration was promoted through a number of vehicles and methodologies. Most importantly, although student research was provided free of charge, all six teams had a local sponsor interested in participating in a more community-based redevelopment process and in providing students with advice, guidance, logistical support, and access to informational resources. The 2008 program involved sponsorship of three city agencies, two NGOs and one private business. The Shaster Foundation and local street committee leadership in a sense sponsored all six project teams as part of their central role in coordinating with WPI faculty the overall engagement of students in the Indlovu Project, but they worked particularly closely with the WPI communications team charged with developing the methods of community engagement discussed below.

The Violence Prevention through Urban Upgrading program [17] of the City of Cape Town and the German Development Bank takes a place-based approach to urban improvement in other areas of Khayelitsha township adjacent to Monwabisi Park. The VPUU, as a city operation with a perspective and capacities that uniquely complement those of the Shaster Foundation, also 
sponsored the overall WPI program and the "mapping" team specifically. This team worked on macro-level urban planning issues (e.g., roads and locating community amenities) and developing a GIS capacity for future research.

The buildings team worked with Ecobeam Technologies, a private company with a low cost, high quality proprietary sandbag and Ecobeam frame building system that local laborers have already used to build two Indlovu Project buildings. The City Water and Sanitation Directorate sponsored the first in what will be a series of WPI teams working to design and implement an experimental communal water and toilet facility, with additional collaboration of WPI and University of Cape Town engineers and social scientists. The City's Office of Sustainable Livelihoods and Greening Programs sponsored the WPI team looking at energy supply and demand issues relative to electricity service, home heating and cooking, insulation, and associated safety risks from the use of paraffin and other fuels for heating and cooking.

The design of the projects - multiple sponsors and an integrated planning perspective - helped our students connect city agencies more closely to community leaders and NGOs working in Monwabisi Park. Those students sponsored by city agencies saw first hand how resource constraints as well as budgetary and political considerations influence service provision in informal settlements [16]. By contrast those students working more closely with shack dwellers learned first hand how many of the city- provided flush toilets in Monwabisi Park were inadequate and contributed to public health and safety risks. And those students who worked with NGOs on macro-level planning and job creation issues, came to understand that an initiative to provide a new water and sanitation facility for local residents, should be designed to provide a range of community benefits - hot water, useful byproducts such as compost for local gardens, a job for a water/public health specialist, a place for people to gather, and so on. The students were in an enviable position compared to many other "redevelopment actors". With no agenda to push and no particular technology to promote, the students were able to create a space for free wheeling discussion and collaboration among the teams and with their sponsors. As one city sponsor told the students: "It's good you had the freedom from institutional restrictions and mindsets that we've got. Being in an organization that's been around here for a few years, we think about why things shouldn't happen and you've thought about how it can happen and we need that to make it work eventually".

The student teams' work was assembled into a draft report that included both individual team chapters and an "integrated plan" chapter prepared by all that set forth a core notion behind the redevelopment strategy: to "grow" change in small, but progressively more rapid incremental steps in situ in a fashion that maximizes public and private benefits while maintaining and strengthening local social networks and decision-making, creates jobs, training and leadership development opportunities, and builds the foundation for a healthier community going forward. The group also presented this integrated plan, based on opportunities arising from cross-sectoral and cross-agency collaboration, to city personnel and community members. 
Important outcomes of this networking included the emergence of a spatially sophisticated, evolutionary strategy for redevelopment that can be illustrated with respect to road design. Rather than adopt the standard approach in which planners working largely outside the community from maps and satellite imagery overlay a rectilinear road grid premised on providing automobile access to all house lots and achieving efficiencies in sewerage line and other utility installations, the mapping team instead devised a much more organic strategy based on their own experiences walking along the maze of paths in Monwabisi Park and observing how local residents used the paths. They recommended an incremental improvement of the existing path network. Roads are to be improved as people and resources are mobilized for redevelopment of small areas within Monwabisi Park, beginning by locating in each of Monwabisi Park's four political subdivisions "redevelopment seeds" - small building clusters comprised of a community centre/public services facility(ies), initial housing stock, and a communal water and sanitation facility.

The redevelopment seed concept serves many critical ends, beginning by posing to the local community and street committee the questions: "What are your priorities for community space? Where will it be located? How will it be managed? How will community members contribute to its construction? How will access to housing be prioritized and under what conditions?" These are difficult questions sure to become entangled in political tensions and factions within the community. In Section $\mathrm{C}$ of Monwabisi Park, however, with the facilitation of the Shaster Foundation, the incentive of public facilities served to strengthen local self-governance and decision-making processes. Furthermore, citizens involved in the construction process learned valuable skills and became familiar with, and supportive of, alternative building techniques. Once completed, the facilities became a locus of community activity, providing vital social, cultural and educational services.

This strategy for growing roads along with village centers places social and political considerations alongside technical ones. The team developed the analytical tools needed to propose a provisional road network able to prioritize serving pedestrians, while providing adequately for emergency and service vehicles and relatively limited numbers of private automobiles. These innovations were possible in part because the mapping team interacted with the sanitation facilities team and knew they were proposing decentralized systems and hence roads need not be wide and straight enough to handle big sewer pipes.

This is one example of the students' efforts to envision a type of in situ upgrading that recognizes Monwabisi Park as an extraordinary and ingenious response to a moment in South Africa's post-apartheid history, where the resources of the state for community development are meager and the scale of the problem immense. It is a recognition shared by a city planner with lengthy experience working in informal settlements, who told the students:

"There's something that happens on the ground that makes informal settlements vibrant places; they're more alive than anything that anyone can ever design. When you intervene, you have to relocate people and that's a serious problem. We never find we can re-engineer the social network and all the 
qualities of spaces throughout the informal settlement. This raises a question. Should the engineer, the architect, the planner, be the architect of everything of urban development or is it just about creating those kernels, those starting points, planting those seeds. And therefore, some actions you leave to people to do on their own accord, to do things in a way that suggests something that can happen, that starts off with an energy but that you leave that choice open to people, and then a thousand decisions that people take over a period of time creates the environment."

This view of a more improvisational process, where trial and error is built into planning, and local residents are seen as resources rather than obstacles to redevelopment [18], aligns with the intent and work of the Cape Town Project Centre. Such a view suggests a need for sustained collaboration within city agencies as well as a means to facilitate communication across domains (community residents, local government, NGOs, academics, etc). Embedded in this comment, however, are a number of thorny challenges. Our work is at an early stage and collaboration is arguably comparatively easy at this point. Little building is underway, political leadership is not fully engaged, the struggle over the allocation of resources has not begun in earnest, and the rules that inevitably must be broken to move what is officially a quasi-legal land occupation toward a higher level of living standards have attracted little attention.

\section{Community engagement}

As we have noted, informal settlements are dynamic, heterogeneous communities in which people have differing needs, capacities and desires. People-centered in situ upgrading efforts such as the Indlovu Project are particularly demanding for undergraduates because such efforts are predicated on deep and sensitive interaction with community members, an ability that few of our students could muster at this point, particularly in cross cultural settings. At the outset of the project, many of our students had little inkling of the cultural and political complexities they would encounter when they began their work in the informal settlements. At least initially, Monwabisi Park, for many of them, was an undifferentiated slum, a place where people (with little personal agency) suffered due to the crushing determinacy of history. But it was also a place, as they saw it, where they would teach people about new technologies, and perhaps, use their technical skills to build a bio-digester or a solar oven, to improve the lives of local residents and to "make a difference". But if in-situ upgrading efforts require a sophisticated approach to communication and sensitive probing to understand the needs and interest of local residents - and to anticipate possible tensions that might emerge - how did we prepare our students to tread carefully and to enlist local residents in redevelopment planning rather than put them off?

To prepare the ground for our students, WPI's engagement with the community began months prior to bringing students to South Africa, when we met with the Shaster Foundation, and then separately with local street committee leaders to discuss the advisability and course of research the students might 
pursue. In part, on the basis of these discussions, we set out to document aspects of existing community conditions that Monwabisi Park residents recognize as strengths and assets worth preserving and those aspects of life people would like to see changed.

To meet these objectives, the WPI communications team worked directly with the Shaster Foundation and street committee leadership to devise modes of community interaction and research methods that served all six teams. We began by engaging a half dozen local residents, men and women who spoke English and Xhosa, as "co-researchers." The co-researchers served initially as community guides, interpreters and key informants as students were introduced to the area and area residents. Accompanied by co-researchers, student teams branched out in Monwabisi Park and conducted detailed interviews with more than a score of local residents, many of whom invited the students into their shacks, as well as small business owners and the owners and customers of local shebeens (illegal taverns). In this way, the students gained an understanding of existing social and physical conditions, and, perhaps more importantly, began to understand the reciprocal nature of the research - that instead of doing the teaching they were also taught a good deal about the residents' views of current conditions, the acceptability of new technologies (e.g., composting toilets, insulated roof panels, the use of new building materials) as well as the importance Monwabisi Park residents attach to the value of community benefits before individual benefit.

The co-researchers were also indispensable to the project because they were able to clarify misperceptions about the students that emerged in the community. Some residents thought the students worked for the city of Cape Town and brought funding to redevelop the settlement. In time, most residents understood the students' status, and for some, the fact that they were students worked to the students' advantage. As one community leader said, "I give thanks especially to these youngsters ...they come from I don't know how many miles, they left their parents, to learn how we are staying here... they left they're parents and that's what makes me more than strong".

Our students' limited experience as researchers in many ways proved to be a strength. Students are generally eager to understand and document others' experiences and viewpoints, and are often perceived as honest brokers, whether documenting views of community members, city personnel, local leaders, etc. And while students often lack the experience to be critical and sophisticated interpreters of what they've heard, they are often adept at documenting viewpoints and presenting them in compelling fashion. The mapping team, for example, conducted community mapping exercises [19] to locate and discuss key existing amenities (e.g., businesses, crèches, churches, taverns), hazards (e.g., flood prone areas, unsafe areas), and travel routes.

These planning exercises, or "charettes" provide a telling example of how engaging the community to identify redevelopment priorities or acceptable design principles can be challenging for students, particularly when deep seated disagreement erupts. At the charette, the students posed various questions about two-story housing. In the course of the meeting, a community leader stated with 
strong conviction the belief that no one should live in a second floor apartment since communing with ancestors requires ritual space on the ground. The students, rather uncritically, adopted this viewpoint as a universal mandate and embedded the preference into housing designs. Only with some pushing would they explore it further and find that many other younger adults had no hesitation to live in two-story housing. Under the influence of the community leader's force of personality, the students framed the issue as a matter of "preservation of culture". This made it harder from them to countenance the economic arguments put forward by younger residents, many of who were temporary migrants from the Eastern Cape, that it was difficult to find lodgings in Monwabisi Park and they wanted to have their own accommodation.

The charettes revealed other fissures in the community on the issue of single family vs. two-story apartment style housing. To provide more housing opportunities, the majority of participants at the charette voiced their approval for two story apartments. The idea touches on certain sustainability principles. Residents living in scattered single shacks in a given "residential seed" would voluntarily move into newly constructed clustered apartments. Once installed in new apartments, their shacks would be dismantled and the residents would gain much needed open space. By increasing residential densities, the community could free up land for gardens and other public amenities, and with more apartments available, persons from outside the "residential seed" could be accommodated in the new design. In the course of the meeting, a young man, a relative newcomer to Monwabisi Park, advocated for single-family units. The man, was forcefully asked to "consider others," and his position was delegitimized as one of a richer newcomer, though clearly he was speaking for a group of younger men, whose position regarding redevelopment may be much different than those of the local women.

The students learned a few lessons from the charette: no one housing option works for everyone and what counts as acceptable housing is likely to vary according to age, gender, income, and length of residence in Monwabisi Park. The students' redevelopment plan was responsive to these perspectives. It prioritized 2 storey housing, but also recognized a range of building types and styles, including single family shacks, sandbag reinforced shacks, unimproved sacks and so on.

The charettes suggest a broader question, and one which our subsequent work in Monwabisi Park will need to grapple with. It is a question the students were asked by a city planner after having seen their final presentation: "The term community is a very elusive concept...for the 20,000 people in Monwabisi Park, who speaks for those people? Does a person or a group have the authority to do so, or are they just neighbors who have a concern about the public common good?" We recognize that critical aspects of local political and institutional dynamics remain largely unexplored in our work. We will continue to rely on our local partners, who themselves assiduously cultivate a non-aligned political posture, to manage difficult tensions upon which many redevelopment efforts founder. 


\section{Capacity development}

For most informal settlements, the influx of financial and other resources that comes with upgrading housing stock and infrastructure represent a critical, rare investment in the community, but rarely do standard redevelopment efforts leverage these investments to strengthen individual and community capacities much beyond offering temporary day labor opportunities for some community members. The Indlovu Project, by contrast, emphasizes leadership development, skills training, and opportunities for people to contribute to community wellbeing as integral to all building projects and service delivery. WPI's 2008 engagement in Monwabisi Park, though lasting only two months, was energized by a commitment not only to embed capacity development measures in all aspects of longer term planning, but to also producing tangible and valued benefits to community members "in real time" during the course of our engagement. This commitment was in equal parts a research methodology (we'd learn crucial lessons faster and more forcefully if we worked with local people to implement certain program elements), a strategic choice (we'd buy credibility and support and get to know people in the community better), and an ethical responsibility (we were always at pains to explain that, while our primary mission was to plan for long-term redevelopment, we had no funding nor authority to make anything happen. Therefore, it was crucial that we in some sense repaid the community for hosting us and furthering our educational and research interests by trying to provide valuable services while in Cape Town).

In many ways, enhancing the capacity of individuals and institutions to set and achieve goals they deem important is the critical distinction between peoplecentered and standard redevelopment methods. A working hypothesis is that the urgency many feel for "proper" homes, toilet, water and jobs, a safer community and better lives for one's children can be a critical asset for redevelopment, if a plausible avenue for its expression can be devised. While development work is rife with examples of failed projects implemented in haste, the same is true of projects implemented through a protracted planning process. Drawing heavily on the experience of our diverse project sponsors, we have therefore tried to devise a redevelopment process that creatively balances working with area residents and collaborating partners to take immediate, tangible steps to address core community needs, with the need for a sufficiently thoughtful long-term strategy for how a healthier community can be "grown" incrementally through such interventions.

Developing capacity in Monwabisis Park has to take into account something of the settlement's improvisational quality. It is a place that many of Monwabisi Park's 20,000 residents consider "home," but is felt as transient to many of its young adults, recently arrived migrants from Eastern Cape Province who have come to Monwabisi Park to look for work in Cape Town and who, given the bleak prospects for gainful employment, are uncertain about how long they are likely to stay. And yet despite this flux of people coming and going, there are strong community networks in place and an ethos of community self-help and solidarity, or ubuntu, which influences the trajectory of planning and 
development initiatives. To better understand community capacity in the context of these two forces in Monwabisi Park, contingency and ubuntu, we developed a number of concrete initiatives discussed below.

As noted earlier, the co-researcher program was designed by WPI and community leadership to first have co-researchers in a facilitative role. They helped students who were new to the community and learning new research techniques themselves to become familiar and comfortable, serving as guides and translators, initial key informants, and helping refine points of inquiry. Soon, however, the protocol changed to co-researchers as principle researchers with students assisting and helping transfer skills, abilities and capacities. Coresearchers conducted interviews and surveys, learned documentary photography and video skills, and some were introduced to computer data entry. With WPI assistance, they launched "Indlovini TV" and began creating video documentaries on pressing social issues (crime, violence prevention, shack fires) that in Xhosa could be played to local audiences as a basis for community engagement on these issues, and in English serve other research and communication interests. The documentaries were of two types: panel discussions with local residents led by one of the co-researchers who proved to be an excellent interviewer, and investigative programs conducted in the field, comprised primarily of interviews but with carefully composed shots of the landscape. Without editing equipment and software, the co-researchers relied on in-camera editing to structure their film. The completed films were shown on a television set in the Indlovu Project's youth centre.

For the co-researchers it was the first time they held in their hands a camera of any sort; not unexpectedly, they were very enthusiastic users of the technology and were adept at constructing compelling narratives in their work with minimal training. The dynamic of the co-researchers and other local residents directing and appearing in documentaries created a new means to probe community attitudes, not only in the making of the programs, but using the programs to spark further conversations with viewers. In the program on violence prevention, for example, violence was understood as a complex social process. And while many of those interviewed were themselves victims of violent crime, they preferred to discuss the root causes of violence - joblessness, mistrust, poverty, the lack of community amenities, the role of policing - and concluded with practical steps to deal with violence through an expanded community watch program. Monwabisis Park residents have expressed interest in making other documentaries on subjects such as HIV awareness and teenage pregnancy.

A second example of skill transfer and capacity building relates to job training. The WPI economy team worked with the building team and their sponsor, Ecobeam Technologies, to plan how to develop a local capacity for making the sandbags and beams used in new housing structures. After conducting a skills inventory of local residents, and discovering that a number of local residents had sewing skills, the team launched a sandbag sewing operation in the community. With Ecobeam as a guaranteed buyer, and with a small hut in the Indlovu Center available to set up a small factory, the WPI team bought two 
industrial sewing machines with funds donated to support WPI's work with communities in Cape Town. The team organized training on the machines for six volunteers. The underlying premise is that by sewing sandbags local residents will supply a primary material for new housing construction and, by selling finished sandbags to Ecobeam at a slight profit, generate income to purchase other construction material and services. In this way, a community-based sewing initiative could be an engine for redevelopment.

These initiatives are taking place in a complex social environment and how they unfold will depend on a number of factors. For example, how will the persons participating in the community video project identify and agree on program ideas - will they put in place a collective where consensus determines programming or will users have freedom to pursue individual projects with little collective oversight? How will roles be assigned? On what basis will the equipment be shared? How can the equipment be safeguarded? And by what means can video help facilitate community deliberations about redevelopment? The sewing initiative similarly raises a host of questions: on what basis should people be selected for training? How should workers be compensated? If one objective is to create the capacity to drive redevelopment, what percentage of the profits from sewing sandbags should be directed to funding community facilities? What principles should be used to manage the sandbag enterprise? At this point, we do not have answers. Rather we will continue to work jointly with Monwabisi Park residents and community groups to understand and refine these complicated questions of implementation and embed them into a long-term redevelopment strategy.

\section{Conclusion}

In this paper we discussed the need for new approaches to sustainable community development in Cape Town's informal settlements and the need for undergraduate STEM students to better understand the complex interplay of social, cultural and environmental dimensions of technological systems and the pursuit of sustainability. In partnering with a dynamic and creative communitybased, NGO-supported initiative in Monwabisi Park, WPI's Cape Town Project Centre has helped catalyze a collaboration among community members, NGOs, city agencies, local business and academic institutions aimed at advancing these congruent interests. The collaboration is very new and we have only begun to understand the complex ways in which "the community" functions, and how its diverse interests, joys, sorrows and needs might meaningfully be addressed through a process of "redevelopment" - not to mention understanding how that process might (must) also satisfy reasonable needs and interests of other parties. While the evidence to date suggests that students have benefited greatly from the experience and that community and city partners also see benefits deriving from the collaboration, we remain aware of how much we don't yet understand and that collaborations involving a diverse social actor network can embody forms of exploitation, if not carefully and openly examined [20]. 
Complexity notwithstanding, if we heard anything at all from our intensive engagement with hundreds of citizens of Monwabisi Park, it was that they were nearly unanimous in wanting some very clear things, including homes that won't regularly leak, flood, burn or sicken them in winter; toilets that are safe, functional and not a daily humiliation to use; water and electricity supplies that are safe, convenient and affordable; opportunities for jobs and learning; and a safer community in which they can continue to enjoy their strong connections with friends, neighbors and family. Furthermore, the overwhelming response was one of generosity of spirit in engaging with students and support for the nascent collaborative effort that they represented.

In just 2 months, the students were able to demonstrate that much could be learned and accomplished. They showed that intensive modes of community engagement and well-received capacity development processes could be set in motion in a short period of time. They prepared a 200 page report and a formal presentation that documented key social and physical conditions in the community and presented options and strategies for change. They did so through the support and guidance of sponsors, community co-researchers, and faculty advisors. This guidance was essential because, while we have suggested that students are a uniquely positioned, under-utilized resource for sustainable development, their openness to new ideas and experiences is partly a function of naiveté. It may be that an essential trick going forward will be to continue to exploit this naiveté, even as the experience is intended to help them grow beyond it, such that students' willingness to bring their creative abilities to bear can help generate new ideas and enthusiasm for addressing what too often can seem like an insurmountable problem.

\section{Acknowledgement}

WPI gratefully acknowledges the GE Foundation's generous support of its work in Cape Town.

\section{References}

[1] South African Cities Network, State of the cities report 2006. 2006.

[2] UN-Habitat, The challenge of slums. Global report on human settlements. 2003, London: Earthscan.

[3] Goebel, A., Sustainable urban development? Low-cost housing challenges in South Africa. Habitat International, 2007. 31(3-4): p. 291-302.

[4] Huchzermeyer, M., Housing for the poor? Negotiated housing policy in South Africa. Habitat International, 2001. 25(3): p. 303-331.

[5] Development Action Group, Upgrading informal settlements: South African policy and praxis. 2007: Cape Town.

[6] Department of Housing. Breaking new ground. 2004 [cited; available from: http://www.housing.gov.za/. 
[7] Abbott, J., Upgrading an informal settlement in Cape Town, South Africa, in Reconsidering informality: Perspectives from urban Africa, K.T. Hansen and M. Vaa, Editors. 2004, Nordiska Afrikainstitutet. p. 193-209.

[8] Baumann, T., Harnessing people's power: Policy-makers' options for scaling up the delivery of housing subsidies via the People's Housing Process. 2003, Housing Finance Resource Programme: Johannesburg.

[9] Winner, L., Do artifacts have politics? in Technology and politics, M.E. Kraft and N.J. Vig, Editors. 1988, Duke University Press: Durham and London. p. 33-53.

[10] Meadowcroft, J., Environmental political economy, technological transitions and the state. New Political Economy, 2005. 10(4): p. 479-498.

[11] Smith, A., A. Stirling, and F. Berkhout, The governance of sustainable socio-technical transitions. Research Policy, 2005. 34(10): p. 1491-1510.

[12] Cash, D.W., et al., Knowledge systems for sustainable development. Proceedings of the National Academy of Sciences of the United States of America, 2003. 100(14): p. 8086-8091.

[13] Clark, W.C., Sustainability science: A room of its own. Proceedings of the National Academy of Sciences, 2007. 104(6): p. 1737-1738.

[14] National Academy of Engineering, The engineer of 2020: Visions of engineering in the new century. 2004, Washington, D.C.: National Academies Press.

[15] Jiusto, S. and D. DiBiasio, Experiential learning environments: Do they prepare our students to be self-directed, life-long learners? Journal of Engineering Education, 2006. 95(3): p. 195-204.

[16] Graham, N., Informal settlement upgrading in Cape Town: Challenges, constraints and contradictions within local government, in Informal settlements: A perpetual challenge? M. Huchzermeyer and A. Karam, Editors. 2007, Juta Academic: Cape Town. p. 231-249.

[17] VPUU. Violence Prevention through Urban Upgrading Programme. 2009 [cited January 24, 2009]; Available from: http://www.vpuu.org/intro.htm.

[18] Mitlin, D., \& Satterthwaite, D., Empowering squatter citizen. Local government, civil society and urban poverty reduction. 2004, London: Earthscan.

[19] WaterAid, Community mapping: A tool for community organising. 2005, London: WaterAid.

[20] Oldfield, S., Who's serving whom? Partners, process, and products in service-learning projects in South African urban geography. Journal of Geography in Higher Education, 2008. 32(2): p. 269 - 285. 